\title{
La cultura en nom del poble? Cap a una tipologia del populisme i la cultura*
}

\author{
Judith Jansma \\ UNIVERSITY OF GRONINGEN \\ j.f.jansmårug.nl
}

Rebut: 26/02/2019

Acceptat: 10/09/2019

\section{RESUM}

Durant les últimes dècades, el populisme ha estat àmpliament estudiat, tot i que des d'una perspectiva majoritàriament política. Les contribucions en aquest camp se centren sobretot en l'anàlisi del populisme com a fenomen sociopolític en el context històric i global. Una altra àrea d'estudi es refereix al suport popular dels partits populistes. Aquesta qüestió, a més de ser de la màxima actualitat, revela les imperfeccions de la democràcia liberal.

Tot i que s'ha dedicat un gran esforç acadèmic a proporcionar una definició de populisme i les raons de l'èxit que té, encara queda per aclarir en quines creences culturals es basen els seus arguments populistes que empren una falsa dicotomia entre «nosaltres» i «ells». Per aquesta raó, després de fer un breu resum del treball acadèmic que s'ha fet fins avui en les disciplines de la ciència política i els estudis culturals, intentarem presentar una tipologia de la cultura i el populisme, que ens ajudarà a entendre per què els diferents aspectes de la cultura (com ara la cultura popular, les imatges culturals i les obres literàries) són de capital importància en la construcció populista del «nosaltres» i l'«ells».

La tipologia es basa en els exemples de França i Holanda (dos països amb importants partits de dreta populista) per a distingir entre sociofacts, mentifacts i artifacts (Huxley) i l'ús que tenen en l'apropiació dels actors populistes. L'última categoria es compon d'allò que anomenarem «autors orgànics» i «autors apropiats», en la terminologia emprada per Gramsci. La diferència entre les dues, com es demostrarà, rau en la identificació de l'autor amb un tipus determinat d'idees, així com en l'articulació d'aquestes.

Paraules clau: estudis culturals, populisme, identitat cultural, França, Països Baixos.

\begin{abstract}
Culture in the Name of the People? Towards a Typology of Populism and Culture
Populism is a topic that has been widely studied over the past decades but mostly from a political perspective. These contributions mainly focus on the analysis of populism as a (socio) political phenomenon placed in a historical, global context. A second field of interest covers the mass appeal of populist parties. The latter is not only a timely, highly relevant issue right now but also sheds light on the flaws of liberal democracy.

While a lot of academic effort has been put into defining populism and explaining the reasons for its success, the underlying cultural beliefs on which populist 'us and them' dichotomies are based remain unclear. We shall therefore come up with a typology of culture and populism. This typology will reveal how various aspects of culture (such as popular culture, cultural images, and literary works) are prevalent in the populist construction of 'us' and 'them'.
\end{abstract}

Based on examples from France and The Netherlands (two countries with major right-wing populist parties), the typology will differentiate between sociofacts, mentifacts and artifacts (cf. Huxley), and their use and appropriation by populist actors. The artifacts category comprises what I call 'organic authors' and 'appropriated authors', a terminology borrowed from Gramsci. The difference between the two, as will be shown, is the author's identification with and articulation of certain kinds of ideas.

Keywords: cultural studies, populism, cultural identity, France, The Netherlands.

\footnotetext{
*Article traduït de l'anglès. El text original està publicat a Debats. Journal on Culture, Power and Society. Annual Review 4.
} 


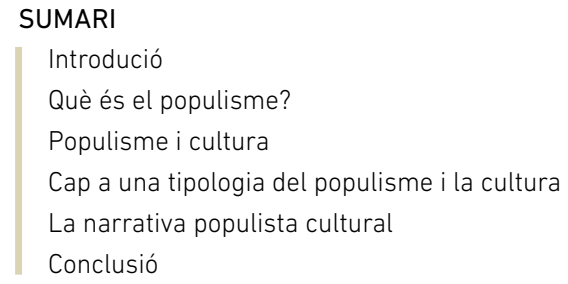

Autor per a correspondència / Corresponding author: J.F. (Judith) Jansma, Faculty of Arts. European Literature and Culture-Centre Arts in Society. Oude Kijk in't Jatstraat, 26. 9712 EK Groningen (Holanda).

Citació suggerida / Suggested citation: Jansma, J. (2019). La cultura en nom del poble? Cap a una tipologia del populisme i la cultura. Debats. Revista de cultura, poder i societat, 133(2), 27-94. DOI: http://doi.org/10.28939/iam.debats.133-2.3

\section{INTRODUCCIÓ}

«Si creus que eres ciutadà del món, no eres ciutadà d'enlloc. És a dir, no entens què significa el concepte de ciutadania.»

Theresa May va fer aquesta famosa declaració poc després del referèndum del Brexit ${ }^{\mathbf{1}}$ i el seu comentari exemplifica la centralitat de la identitat cultural en la política contemporània. La noció d'identitat nacional basada en la cultura ha recobrat actualitat per la importància que té en el discurs polític, no sols entre els partits de la dreta populista, sinó també entre les diverses capes de la societat. Per exemple, en el programa electoral per a les eleccions de 2017, el partit holandés CDA (cristià demòcrata) insistia en el fet que els infants aprengueren a l'escola l'himne nacional i la seua història. Aquesta mesura obligatòria va ser una de les condicions perquè el CDA entrara en el govern de coalició del qual forma part actualment. Per tant, podem dir que es presenta l'adscripció a una identitat nacional com a manera d'afrontar reptes socials complexos, com el multiculturalisme i la globalització.

1 El discurs complet de Theresa May en la convenció del partit: https://www.telegraph.co.uk/news/2016/10/05/theresamays-conference-speech-in-full/
També s'empra la cultura per a comunicar un punt de vista polític. N'és un bon exemple l'intent recent per part de Geert Wilders, ${ }^{2}$ líder del PVV (Partit per la Llibertat), d'organitzar un concurs de còmics sobre el profeta Mahoma que va ser cancel-lat després de les enèrgiques protestes als països musulmans, especialment al Pakistan. En aquest cas va quedar clar que no s'hi pretenia celebrar la cultura per mitjà de l'expressió artística, sinó incitar el conflicte polític, ja que és ben sabut que els musulmans consideren qualsevol representació pictòrica del profeta com una blasfèmia. Wilders va al-legar que va cancel-lar el concurs per protegir els ciutadans holandesos de la ira dels musulmans, als quals considera violents $\mathrm{i}$ intolerants.

Cultura i política formen una combinació molt profitosa, ja que la cultura és un factor essencial per a construir el sentiment de comunitat dins de l'espai geopolític definit (la nació). Segons Anderson (2016),

2 Geert Wilders és el líder d'un partit holandés d'extrema dreta Partij voor de Vrijheid (Partit per la Llibertat), fundat en 2005. Wilders és especialment conegut pel seu discurs anti-islam, pel qual ha sigut enjudiciat diverses vegades. En 2016 va ser condemnat per incitació a l'odi dirigit als ciutadans alemanys d'origen marroquí. 
es pot considerar la nació com «una comunitat política imaginada» en la qual els integrants d'un grup, massa gran perquè tots els membres es coneguen entre si, experimenten un vincle - una «camaraderia horitzontal»- que es basa principalment en una cultura comuna. Com ja hem vist en els exemples anteriors, la cultura pot ser un conjunt de valors i tradicions compartits que ajuden a definir qui som «nosaltres», però també es pot utilitzar per a provocar sentiments hostils cap als «altres». Aquest enfocament fomenta una visió del món polititzada i utilitza la cultura per a promoure uns interessos polítics concrets.

Aquest article proposarà un marc per entendre el paper de la cultura en la política contemporània i se centrarà en els partits populistes, que segueixen un discurs per dividir la societat entre «nosaltres» (bons) $\mathrm{i}$ «ells» (roïns). Aquestes formacions polítiques parteixen del supòsit d'una identitat cultural comuna. D'acord amb el pensament de Rensmann (2017), argumentaré que aquesta noció d'identitat cultural és la que els partits populistes instrumentalitzen per als seus propis objectius. Per aquest motiu (i després d'una breu introducció al populisme i a les dicotomies d'aquest), analitzaré les tàctiques dels populistes per a utilitzar la cultura explícitament com a arma política.

Com que la cultura és un concepte bastant ampli, propose una tipologia que hi inclou diversos tipus i l'ús que en fan els populistes, la qual cosa pot comprendre des de les imatges i els símbols culturals —una interpretació més folklòrica de la cultura- fins a l'ús i l'apropiació d'obres culturals com la literatura, el cine i l'art. Aquest enfocament contribuirà a la comprensió del populisme com a reacció majoritàriament cultural i autoritària de la societat moderna, tal com defén Rensmann (2017).

Després de la primera part més general on definisc el populisme, em centraré principalment en els contextos de França i els Països Baixos. Aquests dos tenen partits populistes de certa magnitud que col-laboren estretament en el Parlament Europeu. En oposar-se a (més) integració europea i a la immigració, aquests partits defenen fortament la seua sobirania i identitat nacional $\mathrm{i}$, per aquesta raó, proporcionen estudis de casos interessants.

\section{QUĖ ÉS EL POPULISME?}

L'any 2016 va marcar l'avanç global del populisme amb la votació del Brexit en juny i les eleccions de Donald Trump en novembre, però la tempestat populista encara no pareix haver-se calmat. L'anomenada "primavera patriòtica» de 2017 es va frenar temporalment a França i als Països Baixos, però tot i així, tant el Front Nacional (FN) com el Partit per la Llibertat (PVV) van quedar en segon lloc en les respectives eleccions presidencials i legislatives. Una «tempestat de tardor» populista va irrompre a Alemanya en setembre de 2017, on Alternativa per Alemanya (AfD) va ser el primer partit nacionalista d'extrema dreta a guanyar escons al Bundestag des de la Segona Guerra Mundial. Tan sols un mes després, quasi el $26 \%$ de l'electorat austríac va votar el partit populista de dreta Partit Liberal d'Àustria (FPÖ), que ara forma part de la coalició d'Àustria. En 2018 uns quants països europeus van experimentar un augment de l'èxit electoral populista, especialment a Itàlia, Hongria, Eslovènia i Suècia. Fora d'Europa, va haver-hi una reelecció molt disputada del president Maduro a Veneçuela, seguida, de l'elecció de Bolsonaro al Brasil el mateix any. En altres paraules, està clar que el populisme continua sent un fenomen polític molt estés dins i fora d'Europa.

Aquest augment del populisme també es reflecteix en l'àmbit acadèmic, com demostra la quantitat de contribucions recents sobre el tema, en especial la publicació en 2017 de Mudde i Kaltwasser: Populism: A Very Short Introduction. La majoria d'acadèmics intenten definir què és el populisme, ja que la paraula s'usa per a descriure fenòmens polítics molt amplis en àrees geogràfiques i tradicions polítiques molt diferents, des de presidents d'esquerra llatinoamericans fins a partits d'extrema dreta europeus (Mudde i Kaltwasser, 2017). En conseqüència, pareix haver-hi poc consens sobre si el populisme és una ideologia, un moviment, 
un estil polític o un discurs. Per a aquest article em quede amb la definició minimalista de Mudde (2004). Aquesta, a més d'incorporar els conceptes centrals que són comuns a tots els populismes, també reconeix les diverses formes que pot adoptar. Mudde i Kaltwasser (2017: 6) el defineixen de la manera següent:

El populisme és una ideologia prima i considera que la societat està bàsicament separada en dos camps homogenis i antagònics, «el poble pur» i «l'elit corrupta», i argumenta que la política hauria de ser una expressió de la volonté générale (voluntat popular).

Aquesta definició o enfocament conceptual entén el populisme com una ideologia «prima», en contrast amb una ideologia «completa», la qual cosa significa que es pot combinar amb altres. Si el populisme determina la presència dels tres conceptes centrals, les «ideologies de l'hoste» defineixen la forma en què s'interpreten. Per exemple, si el populisme es fusiona amb el socialisme, formar part de la gent o l'elit és principalment una qüestió socioeconòmica; a Llatinoamèrica, a països com Veneçuela i Bolívia, o a Europa, en partits populistes d'esquerra com Podemos, a Espanya, i Syriza, a Grècia. D'altra banda, quan el populisme es combina amb el nativisme, el poble es constitueix sobre una base ètnica; per exemple, els «verdaders» francesos, hongaresos o estatunidencs, i se n'exclouen minories com els gitanos o els immigrants musulmans.

Una altra qüestió molt debatuda és per què les persones voten els partits populistes i, específicament, què les anima a votar-los de manera tan nombrosa avui dia. Com argumentava Laclau en la seua influent obra On Populist Reason (2005), el populisme sorgeix quan hi ha una «multiplicació de les demandes socials». No obstant això, aquestes demandes socials o «preocupacions desateses» (Judis, 2016) són nombroses $i$, per tant, sovint es classifiquen segons les divisions socials o culturals de la societat (Kriesi et al., 2006; Rensmann, 2017; Rodrik, 2017). En general, podríem afirmar que els votants populistes es rebel-len contra l'establishment perquè senten que la seua forma de vida està amenaçada o és injusta. No obstant això, la naturalesa exacta d'aquests desafiaments pot variar entre països, regions i, probablement, fins i tot entre les diverses persones.

La cosmovisió populista simplifica una realitat complexa, tot explicant els problemes d'un poble homogeni imaginari, culpant-ne l'elit i convertint els «altres» en boc expiatori. Aquesta idea d'antagonisme és clau en les teories sobre populisme i produeix les dicotomies horitzontals i verticals (Rensmann, 2017). La dicotomia vertical entre el poble i l'elit és una part essencial del populisme. Els populistes argumenten que l'elit, que pot ser política, econòmica o cultural, està allunyada de la gent comuna (Rooduijn et al., 2016) i, per tant, ja no representa el poble. Això, segons l'opinió populista, és el món al revés perquè la idea de sobirania popular implica que la voluntat del poble o la voluntat general han de ser decisives. En el vídeo de campanya ${ }^{3}$ de 2017 , Marine Le Pen - líder del partit d'extrema dreta francés Front Nacional- il.lustra aquest antagonisme quan diu a la seua audiència que l'opció que trien en les eleccions és crucial. En les seues pròpies paraules, «un choix de civilisation» (l'elecció de la civilització). L'elecció, va dir, és continuar votant «els que van mentir, fracassar, trair, enganyar la gent i van perdre França» o donar suport a altres per «posar França novament en ordre». Com que el lema de la campanya va ser «Au nom du peuple» (en nom del poble), no cal molta imaginació per a saber qui són els mentiders i traïdors, i per què els francesos necessiten Marine Le Pen perquè França siga «independent, respectada, pròspera, orgullosa, sostenible i justa».

A més d'oposar el poble a les elits, la majoria dels populistes tendeixen a excloure un «altre» de formar part del poble. Aquest mecanisme es coneix com dicotomia horitzontal (Rensmann, 2017) o exclusionisme (Rooduijn et al., 2014). Tot i que alguns acadèmics sostenen que aquesta exclusió d'un «altre» perillós és purament una característica del populisme de dreta (Judis, 2016; Mudde, 2013; Rooduijn et al.,

3 Fragment de vídeo de la campanya oficial de Marine Le Pen (2017): https://www.youtube.com/watch?v=FYWnuQc5mYA 
2014), Rensmann no hi està d'acord i afirma que aquest discurs excloent també es troba en partits populistes que generalment es defineixen d'esquerra. Assenyala els alemanys Die Linke (L'Esquerra) i França Insubmisa que, malgrat que se situen a l'(extrema) esquerra de l'espectre polític, sí que defenen un programa obertament nacionalista. Hi afegeix que, en última instància, la classificació esquerra-dreta és una ferramenta inadequada per a qualificar diferents tipus de populisme i suggereix que n'analitzem altres aspectes:

No obstant això, malgrat les distincions transnacionals, tots els actors populistes «de dreta» i la majoria «d'esquerra» comparteixen denominadors ideològics comuns clau basats en l'autoritarisme, les dicotomies verticals i horitzontals antiliberals que protegeixen, implícitament o explícitament, l'exclusivitat cultural, la identitat i la denigració dels «altres». (Rensmann: 126)

En altres paraules, i si tornem a la definició de populisme de Mudde (2004) com una ideologia «prima», l'adopció o el rebuig de les idees nativistes no determina si un partit populista és d'esquerra o de dreta. En realitat, el simple fet que el populisme faça referència a un poble homogeni imaginari suggereix que algun tipus d'exclusió és inherent a la visió populista, ja que aquests pobles homogenis no existeixen $i$, per tant, es creen quan se n'exclouen membres que es veuen o es comporten de manera diferent.

De la mateixa manera que la dicotomia vertical —en la qual els populistes subratllen la distància percebuda entre la gent i l'elit i, el més important, la falta de voluntat de l'elit per a reduir-la-, la dicotomia horitzontal és multicapa. Segons les idees populistes, $l^{\prime}$ «altre» constitueix una amenaça seriosa per a la gent homogènia imaginada, la qual cosa implica que la gent és moralment bona i l'«altre» inherentment roí. És important assenyalar que l'«altre» també es projecta com una entitat homogènia, igual que les persones i l'elit. Evidentment, aquesta homogeneïtzació de l'«altre» és molt problemàtica, especialment quan es parla de grups com persones «immigrants» $\mathrm{o}$ «refugiats» que, òbviament, estan formats per gent de diverses nacionalitats, religions, antecedents socioeconòmics i amb nivells d'educació diferents. En definir un grup extern, se'n forma un de propi sobre la base d'una dicotomia: «són immigrants mandrosos» en oposició a «som bons treballadors». Excloure l'altre ajuda a construir una identitat pròpia (nacional) (Wodak, 2015).

La meua suposició és que aquest doble mecanisme de «nosaltres contra ells» tan freqüent en la visió populista es basa en una comprensió cultural de la identitat comuna de les persones a la qual contribueix. Per això, aquesta ponència se centrarà en les formes en què el populisme i la cultura estan interrelacionats. Sovint es pensa que són mútuament excloents: el populisme descarta la cultura com una pèrdua de temps i diners, mentre que la cultura percep i representa el populisme com el seu «altre» inquietant. Argumentaré que la realitat és molt més complexa. La següent part proporcionarà una visió general de les contribucions acadèmiques (recents) sobre el populisme i la cultura, i seguidament faré una aproximació a l'ús i l'apropiació de la cultura per part dels populistes.

\section{POPULISME I CULTURA}

Ja en 2006, Kriesi et al. van mencionar la prevalença de factors culturals sobre els econòmics en el programa de la dreta populista $i$, en contribucions acadèmiques recents, aquesta idea s'ha generalitzat cada vegada més. En l'article, Kriesi et al. (2006) conclouen que «els partits de la dreta populista no destaquen pel seu perfil econòmic» i que «és en qüestions culturals on donen suport a una estratègia de demarcació molt més forta que els partits convencionals (no transformats)». Centrant-se en la dreta populista, afirmen que aquest èmfasi en temes culturals és una eina molt més eficaç per a unir un gran grup de persones desil-lusionades de perfils econòmics molt diferents.

Aquesta idea d'una escissió econòmica i cultural també està present en Rodrik (2017), que divideix 
la realitat entre els "guanyadors» i els «perdedors» de la globalització. Mentre que el primer és una característica del populisme d'esquerres —en què s'accentua el cisma entre la classe treballadora i les elits (financeres)—, el segon explota la bretxa cultural basada en la identitat del «poble» davant de grups externs, com immigrants i tecnòcrates, $\mathrm{i}$ de les institucions (UE) que permeten que ocórrega aquest flux de «competidors». La divisió entre els factors econòmics i culturals que expliquen el vot populista també pot trobar-se en Gidron i Hall (2017: 6), que analitzen la dreta populista. El seu enfocament principal és l'estatus social subjectiu de cada individu. Ells suposen que tant els desenvolupaments socioeconòmics com els nous marcs culturals (és a dir, el multiculturalisme i la igualtat de gènere) tenen un impacte negatiu en els sentiments de les persones de ser respectades i reconegudes en la societat. La distinció de Goodhart (2017: 9) entre Somewheres (gent amb arrelament geogràfic) i Anywheres (gent sense arrelament geogràfic) suggereix un sentiment d'inferioritat per part dels primers (la gent comuna) davant dels segons (l'elit) i afirma que el descontentament rau principalment en els valors culturals:

L'atracció del populisme (des del punt de vista polític) està motivada, principalment, per l'ansietat cultural i la pèrdua psicològica difícilment avaluable. El factor econòmic també hi té un paper, tot i que potser menys important del que s'esperaria. La raó per pensar-ho és que el $56 \%$ dels britànics que van votar a favor del Brexit procedien de les classes menys acomodades. Si el factor econòmic haguera sigut important per a aquests votants, s'esperaria que els populistes d'esquerres, partidaris d'eixir de la UE, hagueren sigut més rellevants en el referèndum.

Els diferents conjunts de valors culturals (progressistes versus conservadors) provoquen enfrontaments: una «reacció cultural» (Inglehart i Norris, 2016), «guerres culturals» (Furedi, 2018; Nagle, 2017) o, en paraules de Rensmann (2017), una «contrarevolució cultural». Com a tal, el populisme parla a les persones, les veus de les quals van pertànyer en algun moment al discurs normatiu cultural dominant, però ara són anul-lades per aquells que defenen els valors socials progressistes.

El xoc cultural també es pot esdevenir en l'àmbit internacional. Furedi (2018) descriu «actituds conflictives cap als valors culturals» entre Hongria, liderada per un partit populista de dreta conservador, i la UE. Al mateix temps, molts partits populistes d'Europa occidental tenen una forta tendència a contrastar els «nostres» valors occidentals moderns amb els de l'«altre», generalment una cultura islàmica, considerada retardada (Brubaker, 2017; Moffitt, 2017). Es defén un «cristianisme identitari», una «cultura» comuna d'Europa occidental que inclou valors progressistes liberals com ara la igualtat de gènere, els drets dels homosexuals, el laïcisme i la llibertat d'expressió enfront de l'islam (suposadament intolerant). Aquests exemples mostren clarament que la cultura és una eina essencial per a la mobilització de la gent i que juga amb el seu descontentament i els seus valors culturals canviants.

En el camp dels estudis culturals també apareix el terme populisme, sobretot en relació amb la cultura popular. McGuigan (1992: 4) invoca la noció de «populisme cultural» i busca subratllar la importància d'estudiar les experiències i pràctiques simbòliques de la gent comuna en contrast amb «la cultura, amb una $\mathrm{C}$ majúscula». S'hi pot veure un paral-lelisme entre aquesta concepció neogramsciana dels estudis culturals i la dicotomia vertical de les persones oposades a l'elit. També val la pena mencionar ací el fenomen literari de le roman populiste a principis de la dècada de 1930 a França (Paveau, 1998). Segons els autors dels dos manifestos - Thérive i Lemonnier-, la gent ha de tenir un lloc central en la narració (Lemonnier, 1930; citat en Paveau, 1998: 48): «(..) cal representar les persones humils, les persones mediocres, que són la massa de la societat i tenen vides que també contenen els seus drames».

Més recentment, Bax (2016) va adoptar el terme «populista literari» per descriure el treball del novel-lista holandés Leon de Winter, que utilitza una retòrica 
populista per a posicionar-se com a intel-lectual públic i celebritat literària. L'intel-lectual públic escriu columnes per a diaris i el conviden a programes d'entrevistes com a comentarista polític, mentre que la celebritat literària, que busca l'èxit comercial, vol que els seus llibres siguen un pur entreteniment. Amb el suport del públic lector (el poble) i denunciat pels crítics literaris (l'elit), Bax identifica una similitud amb el polític populista i la seua retòrica que també es reflecteix en les novel-les polítiques de De Winter. Els tres exemples comparteixen el desig de l'autor d'identificar-se amb les persones i la seua forma de vida, que es percep més autèntica. No obstant això, tot i que s'empre el terme populisme, ha de quedar clar que aquesta interpretació no està en consonància amb la definició que en fa Mudde (2014) (vegeu més amunt), sinó que l'accent es posa en alguns dels seus aspectes clau. En el cas de le roman populiste, l'èmfasi d'aquestes persones es pren del fenomen populista rus de principis del segle xx: els naródnik. Bax, d'altra banda, se centra en les eines retòriques populistes de simplificació i polarització que integren l'obra de De Winter. Aquest fet indica fins a quin punt el populisme s'ha convertit en un terme ambigu utilitzat en diferents disciplines i ens recorda que hem de ser conscients dels diversos usos i accepcions que té.

En compte de fer-se ressò d'un fenomen polític, la cultura de vegades pot ajudar-nos a comprendre o a reflexionar sobre les realitats (polítiques) complexes i els valors culturals en joc. Un d'aquests exemples és l'anomenat «colp de Trump», la sobtada popularitat de certes novel-les distòpiques després de l'elecció de Donald Trump com a president dels Estats Units. Shaw (2018) i Rau (2018) contemplen l'aparició d'un nou gènere literari de novel-les posteriors al Brexit (BrexLit) i analitzen les lliçons que se'n poden aprendre. De manera semblant, segons Berg-Sørensen (2017), la cultura pot servir com a «diagnòstic d'una crisi ideològica actual en la cultura democràtica europea». Pel que fa a la controvertida novel-la Submissió (2015: 143), d'Houellebecq, especifica que l'autor usa la sàtira per a «exposar, burlar-se, fer-nos riure, desemmascarar $i$, per tant, criticar els que estan en el poder i tenen l'autoritat».
En resum, hem vist que la cultura i el populisme s'estudien com a temes interrelacionats, tot i que hi ha distintes maneres d'estudiar aquesta interrelació. La connexió més freqüent és la que hi ha entre la importància del descontentament cultural que alimenta l'èxit del populisme. Menys estudiats són els paral-lelismes entre el populisme i la cultura popular, i el paper de la cultura i la literatura com una forma de reflexionar críticament sobre el món. No obstant això, queda per fer una anàlisi profunda de l'ús real de la cultura que fan els populistes. Un estudi del cas anterior va revelar que els membres del Front Nacional i els periodistes de dretes es referien a Submissió com un senyal d'advertència i deien implícitament a les seues audiències que votaren per una eixida política (Jansma, 2018). Per tenir una idea més clara d'aquesta apropiació de la cultura per part dels partits populistes, a continuació elaborarem una tipologia de populisme i cultura.

\section{CAP A UNA TIPOLOGIA DEL POPULISME I LA CULTURA}

Abans de passar a analitzar la narrativa cultural populista, cal reflexionar sobre la noció de cultura i sobre les formes en què pot ser una eina útil per als populistes en particular. Segons Hall (1986: 26), la cultura inclou:

(...) el terreny real de les pràctiques, les representacions, els idiomes i els costums de qualsevol societat específica. També em referisc a les formes contradictòries del «sentit comú» que han arrelat $\mathrm{i}$ han ajudat a donar forma a la vida popular.

Aquest enfocament antropològic implica que la cultura es considera un sistema de «significats socials compartits» (Barker, 2000: 8), en contraposició al concepte de cultura amb una $\mathrm{C}$ majúscula (vegeu leavisisme). Aquesta última interpretació (elitista) veu la cultura com «el millor que s'ha pensat i dit en el món» (Arnold, 1960; citat en Barker, 2000: 36). En altres paraules, l'oposició entre la cultura «alta» i la «baixa» fa referència a la qüestió de si la cultura ha de veure's com «el punt culminant de la civilització» (Barker, 2000: 36) o el producte de la vida ordinària. 
Tradicionalment, es poden distingir tres tipus de cultura (Barker, 2000; McGuigan, 1992; Nachbar i Lause, 1996: 16): la cultura d'elit, la cultura popular i la cultura folklòrica. Mentre que aquesta última és més aviat una transmissió d'elements culturals en què s'inclouen les llegendes o les receptes familiars, dins d'una comunitat reduïda (família, amics), les altres dues són de naturalesa pública. La diferència principal entre la cultura popular i la d'elit, segons Nachbar i Lause, és que la primera es produeix a gran escala i té per objectiu arribar a tant públic com siga possible, i la d'elit, d'altra banda, apunta a una audiència més exclusiva, amb interessos o coneixements específics. Els autors destaquen la seua convicció que la intel-ligència i la riquesa no són ingredients necessaris per a la cultura d'elit: «l'“elit” fa referència a aquells suficientment interessats a aprendre el coneixement específic necessari i no només a la cultura dels rics i intel-lectuals».

Evidentment, aquesta distinció entre la cultura popular, folklòrica i d'elit no és clara en absolut. El director d'una pel-lícula d'art i assaig també tindrà per objectiu vendre tantes entrades com siga possible per fer-la rendible i un oient experimentat de Bach probablement necessitarà constància per poder processar la música pop convencional (i viceversa). Això mostra els límits de capturar el concepte complex de cultura en categories ben definides (jeràrquiques) i explica les discussions eternes sobre, per exemple, què es considera art i què no. Encara que aquesta classificació de la cultura dista de ser ideal, ens proporciona un bon punt de partida per a la negociació del poder i la cultura. Hi entren en joc els conceptes gramscians d'ideologia i hegemonia o, en altres paraules, la concepció que les idees hegemòniques són les idees de la classe dominant. Així doncs, com que la ideologia i l'hegemonia són factors inestables, la cultura és «un terreny de conflicte i lluita pels significats» (Barker, 2000: 60-61). La cultura popular és molt rellevant pel que fa a aquests dos conceptes, ja que es basa en allò que Gramsci anomena «sentit comú» o «mentalitat cultural» (Nachbar i Lause). L'estudi de la cultura popular no està tan interessat en el valor estètic de l'element, sinó que se centra en les creences i els valors culturals que hi ha al darrere i en com les persones hi reaccionen. És fàcil veure el paral-lelisme entre aquesta concepció neogramsciana dels estudis culturals i la dicotomia vertical del poble i l'elit. Aquest ha sigut, i continua sent, un tema d'interés en l'estudi del populisme (Hall, 1985, 1986; Laclau, 2005; Hart, 2012). No obstant això, abans d'analitzar diversos exemples d'usos populistes de la cultura, és essencial fer l'anàlisi dels mecanismes per crear una identitat nacional sobre la base dels valors i les creences compartides.

Si, com afirma Anderson, considerem que la base d'una comunitat és principalment cultural i interpretem la cultura com la totalitat de valors i creences compartides, aleshores la pregunta és: com s'aplica això al discurs populista? Com s'ha discutit anteriorment, el populisme és una ideologia prima i basada en tres conceptes centrals: la gent, l'elit i la voluntat general. He afirmat que el concepte d'un poble homogeni és intrínsecament exclusiu i està constituït entorn dels principis d'una cultura comuna. Per tant, aquest component cultural no es limita a l'extrema dreta, sinó que definitivament s'expressa d'una manera més explícita en partits amb un fort caràcter nativista, com el Front Nacional i el Partit per la Llibertat. A més d'un «altre» diferent, que es percep com algú que posa en perill la cultura nacional de la gent, l'elit és demonitzada perquè no pot o no vol protegir el país de perdre la seua identitat. En un discurs a les jornades de Frejús el 18 de setembre de $2016,{ }^{\mathbf{4}}$ Marine Le Pen va articular el vincle purament cultural entre els francesos:

El poble francés eres tu i som nosaltres. Som milions d'homes i dones fonamentalment units per vincles invisibles però irreductibles, units per l'amor a un país, per l'afecció a un idioma i a una cultura. Un poble és un sol cor que batega en milions de pits, és el mateix alé i una mateixa esperança.

4 Discurs de Marine Le Pen a les jornades de Frejús: https:// www.rassemblementnational.fr/vídeos/discours-de-marinele-pen-aux-estivales-de-frejus/ 
La cultura és en aquest cas una eina per a unir les persones sobre la base d'un conjunt de denominadors comuns. És distintiva, perquè permet que les persones es definisquen a elles mateixes com a franceses i alhora les distingeix d'altres pobles (els britànics o els alemanys). La cultura no només és un instrument distintiu per a definir el jo, sinó que és la cinquena essència de l'existència de les persones i els seus valors com a tals: «Què és França si no és una França lliure, no alineada, sempre dempeus quan es tracta de garantir la llibertat de les persones per escollir el seu destí?» (Marine Le Pen, 18 de setembre de 2016).

La resposta a aquesta pregunta retòrica és, per descomptat, bastant òbvia i destaca la idea que, sense la definició populista de la cultura, la noció del francés no és més que una corfa buida. Una transformació del sistema de valors i creences compartides condueix inevitablement a la pèrdua de la identificació amb la cultura i, per tant, la funció distintiva d'aquesta, i fins i tot a un desinterés cap als èxits de l'Estat democràtic, com la llibertat, la igualtat i la fraternitat. Aquest fet està estretament relacionat amb la tercera i última implicació de la definició populista de cultura: el caràcter hegemònic. Altres cultures, especialment les no europees, són intrínsecament retardades, vegeu la citació següent de Geert Wilders, del 13 d'abril de 2015, durant una reunió de Pegida, ${ }^{\mathbf{5}}$ a Dresden, Alemanya: ${ }^{6}$ «La nostra cultura pròpia és la millor cultura. I els immigrants haurien d'assumir els nostres valors i no a la inversa». Això es relaciona amb la noció de Leitkultur, la cultura líder d'un país que els nouvinguts haurien d'assimilar (Ossewaarde, 2014). Curiosament, Wilders considera que les cultures alemanya i holandesa són igual de bones, ja que ambdues es funden en l'anomenada tradició judeocristiana; s'oposa a les cultures immigrants - $\mathrm{i}$ apunta implícitament a l'islam-que representen

5 Acrònim de Patriotische Europäer gegen die Islamisierung des Abendlandes (Patriotes Europeus contra la Islamització d'Occident), un moviment d'extrema dreta fundat originalment a Dresden (Alemanya) l'any 2014.

6 Text del discurs de Geert Wilders al Pegida del 13 d'abril de 2015: https://www.pvv.nl/36-fj-related/geert-wilders/8286speech-gw-pegida-130415.html un perill per a les nostres cultures, suposadament superiors, d'Europa occidental.

Els exemples anteriors mostren com, segons els líders populistes, la cultura no sols és distintiva per a certes persones, sinó també per l'excel-lència i força hegemònica. No obstant això, encara no està clar com es tradueix això en una narrativa cultural populista, de la qual cosa parlarem en la pròxima secció.

\section{LA NARRATIVA POPULISTA CULTURAL}

Per a distingir les idees i tradicions, d'una banda, dels productes concrets, de l'altra, utilitzaré la terminologia sociofacts, mentifacts i artifacts, de Huxley (1955). Les dues primeres s'apliquen a allò que ell anomena construccions socials i mentals, com ara el parentiu i les institucions polítiques. Les construccions econòmiques formarien part dels sociofacts, mentre que els símbols, els rituals i les creences correspondrien als mentifacts. Entre els exemples d'artifacts, hi ha edificis, utensilis, vehicles, etc. Sobre aquests últims, Huxley (1955: 17) escriu el següent: «(...) es classifiquen d'acord amb les necessitats i els desigs humans que satisfan: alimentació, salut, habitatge, roba, oci, adorns, comunicació, etc.».

En altres paraules, mentre que els mentifacts inclouen els valors i les creences compartits d'una determinada cultura, els sociofacts fan referència a com aquestes idees es reflecteixen en estructures socials visibles, i els artifacts constitueixen les produccions materials d'una cultura determinada. Per al propòsit d'aquest article, la definició d'artifacts es reduirà a produccions artístiques, ja que ens interessen els productes dirigits a la nostra imaginació i a les nostres emocions.

Un exemple de sociofact a França i als Països Baixos són les festivitats judeocristianes, especialment el Nadal. Tant el FN com el PVV comparteixen la idea de l'amenaça d'una societat multicultural on no hi ha lloc per a les festivitats religioses tradicionals. Un membre del parlament de PVV fins i tot parla d'una 


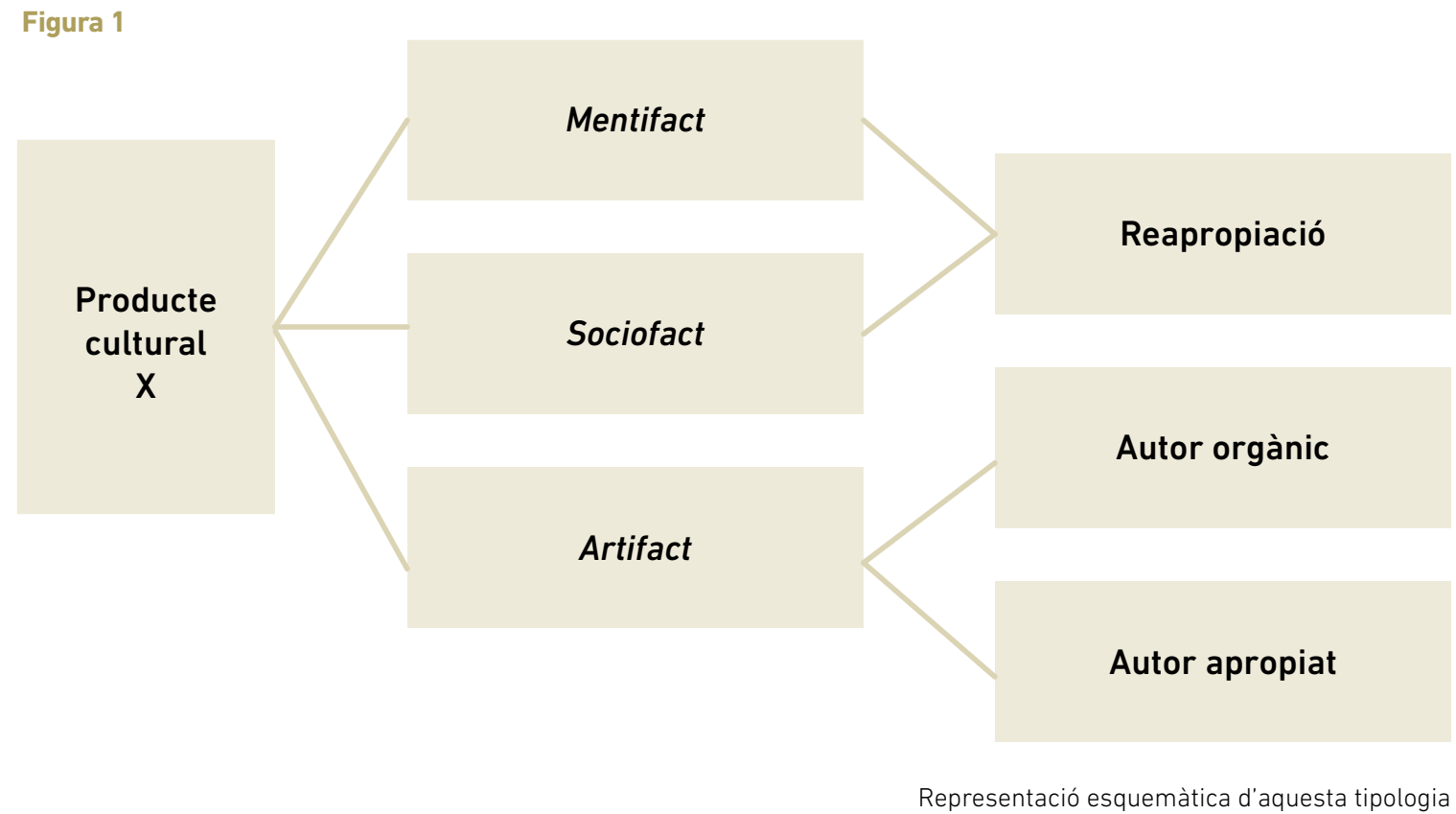

«guerra cultural contra la nostra identitat». ${ }^{7}$ La idea principal d'intentar ser més inclusius amb els grups no cristians és contraproduent. Exemples d'aquesta política són l'intent de canviar «Nadal» per «Festa d'hivern» $\mathbf{i}$ «ous de Pasqua» per «jugar a l'amagatall dels ous» (joc infantil). Els aspectes cristians tradicionals i, per tant, la «nostra» cultura, s'estan perdent. Aquesta idea de secularització amb l'objectiu de més inclusió (o potser més èxit comercial) també està present a França i està estretament relacionada amb la presència dels tradicionals crèches de Noël (pessebres) a llocs públics i la (in)compatibilitat amb les nocions de laïcisme. Com que es considera una expressió de la cultura francesa, l'objectiu del FN és protegir la presència d'aquests pessebres en edificis públics com els ajuntaments que, segons el principi de laïcisme, no han de contenir expressions religioses.

Aquesta idea de laïcitat, o la separació entre l'Estat i l'Església, podria considerar-se un mentifact, ja

7 Pere el Negre (Zwarte Piet): https://www.pvv.nl/75-fj-related/ harm-beertema/9440-zwarte-piet-wet.html que és un valor abstracte característic i clau de la societat francesa. En institucionalitzar-se per mitjà de la llei de 1905, aquest valor va trobar una manifestació més concreta en l'àmbit dels sociofacts. No obstant això, és important tenir en compte que el que es converteix freqüentment en tema de debat no és aquesta llei específica, sinó la mera creença subjacent en aquesta noció de laïcitat originada en la Revolució Francesa. L'exemple més fàcil és la prohibició del burquini (vestit de bany que, a diferència del biquini, tapa quasi tot el cos) que es va instaurar en algunes platges franceses l'estiu de 2016, la qual cosa va comportar que la policia haguera d'obligar les dones musulmanes a no utilitzar-lo. Tanmateix, en altres llocs com ara els Països Baixos, on la laïcitat no està explícitament protegida per la llei, han sorgit discussions sobre la compatibilitat de la «nostra» societat occidental i l'islam i els «seus» símbols religiosos. En 2009, Geert Wilders va introduir la noció de Kopvoddentaks, o «impost de drap per al cap», un nom molt pejoratiu per a un impost que s'aplicaria a aquelles persones disposades a portar mocadors al cap en públic. 
En general, hi podem observar una interpretació equívoca del laïcisme. En el cas de Marine Le Pen, això es tradueix en el rebuig dels principis d'aquest si parlem de la presència de certs objectes religiosos que formen part de la tradició judeocristiana, com els pessebres que hem esmentat més amunt. No obstant això, quan es parla de l'islam, ella és una feroç defensora del laïcisme i està disposada a prohibir objectes religiosos com els mocadors al cap en la vida pública. Aquest fet mostra com la idea del «cristianisme identitari» funciona en la pràctica, en relació amb les festes o tradicions judeocristianes com a part de la nostra cultura (europea) i sempre acusa altres religions i cultures $\mathrm{d}^{\prime}$ «intolerants», la influència de les quals ha de restringir-se (Wodak et al., 2013).

Una característica important que tenen en comú els mentifacts i els sociofacts és la idea de la reapropiació dels esdeveniments històrics, els símbols o les figures. Això està en línia amb l'anàlisi de Renan (1882) d'allò que defineix ser un poble: «tenir glòries comunes en el passat i la voluntat de continuar-les en el present, havent fet grans coses junts i desitjant tornar-les a fer». Aquest gloriós passat es construeix, no només per mitjà de la memòria, sinó que l'oblit també n'és un altre factor important. Renan considera l'essència d'una nació el fet que «tots els membres tenen molt en comú i també que han oblidat moltes coses». El concepte d'oblit implica qüestions pràctiques —com ara pertànyer a un grup ètnic els orígens del qual es mesclen necessàriament al llarg de la història—, però també comprén l'oblit d'esdeveniments històrics dels quals u no hauria d'estar-ne orgullós, com les guerres colonials o, segons l'exemple de Renan, la massacre del dia de sant Bartomeu. La noció de Hobsbawm (2012) de «tradicions inventades» - la construcció de valors i normes de comportament que es repeteixen i pareixen ser continus amb el passat- està relacionada amb l'oblit. En altres paraules, una certa tradició (mentifact o sociofact) ocorre de forma regular i existeix presumiblement perquè les coses es van fer d'aquesta manera en el passat llunyà. La part problemàtica no és la tradició inventada, sinó la creença inviolable en l'autenticitat d'aquesta (que és falsa), el menyspreu cap a passats alternatius i la idea que l'única manera de mantenir-se fidel a la cultura és celebrar-ho en la «forma pura». Això, com hem vist anteriorment, fa que les tradicions inventades siguen el camp de joc dels partits populistes, que al-leguen que els «altres» $\mathrm{i}$ l'«elit» volen destruir-les i, amb això, implícitament, rebutjar una part important de la cultura nacional.

Així mateix, Anderson (2016) destaca la importància d'allò que ell anomena emplotment (crear un relat esbiaixat i interessat) de la història, la creació d'una narrativa històrica que emfatitza una fraternitat imaginada, en la qual l'oblit té un paper crucial (p. 210):

Els llibres de text d'història en anglés ofereixen el divertit espectacle d'un gran Pare Fundador i s'ensenya els escolars a anomenar-lo Guillem el Conqueridor. No se'ls informa que Guillem no parlava anglés - de fet no podria haver-ho fet, ja que l'idioma anglés no existia en la aquella època- ni es diu «Conqueridor, de què?». Perquè l'única resposta moderna intel-ligible hauria de ser «Conqueridor dels anglesos», la qual cosa convertiria el vell depredador normand en un precursor de Napoleó o Hitler amb més èxit.

Aquesta reapropiació d'importants esdeveniments històrics, figures o símbols, no només constitueix la idea d'una història nacional comuna, sinó que és un precedent per als reptes actuals. En paraules de Renan: «la voluntat de continuar les glòries del passat en el present». Aquests reptes estan relacionats amb la presència de $l^{\prime}$ «altre» estranger i la dicotomia horitzontal. Tant el FN com el PVV insisteixen en l'amenaça potencial que representa l'islam per a les creences i els valors (judeocristians) dels francesos i els holandesos. Curiosament, en observar els discursos dels líders populistes, poden trobar-se molts paral-lelismes amb els esdeveniments històrics que involucren la dicotomia «nosaltres contra ells».

Wilders va fer referència a l'imperialisme anomenant els ciutadans holandesos d'origen marroquí «colons», ${ }^{\mathbf{8}}$

8 Entrada de Wilders durant ABP: https://www.pvv.nl/12-in-dekamer/spreekteksten/1288-inbreng-wilders-tijdens-apb.html 
parlant d'una «infiltració de la xaria» ${ }^{9}$ i insinuant l'aparició d' «Eurabia» ${ }^{\mathbf{1 0}}$ durant el discurs final del seu judici. Wilders també traça un paral-lelisme històric amb el nazisme, comparant l'Alcorà amb Mein Kampf,'11 $i$ afirma que el primer conté encara més antisemitisme i crides a l'odi i a la violència que el llibre nazi. El nouvingut Thierry Baudet (Fòrum per a la Democràcia) es refereix al nazisme d'una manera una mica més subtil, sense esmentar-lo explícitament. Remarca la «puresa» de les civilitzacions i adverteix els immigrants, que, segons ell, són la raó de la «dilució homeopàtica»o el debilitament de la civilització occidental.

El predecessor de Wilders, Pim Fortuyn, va ser el primer polític holandés que va qüestionar obertament l'islam i la societat multicultural, fet que va comportar que l'assassinaren l'any 2002. Va parlar de «croades»12 per referir-se a les lluites contra el fonamentalisme islàmic, de manera que vinculava els esdeveniments recents amb les guerres religioses medievals. La seua columna acaba amb unes paraules significatives: «la història es repeteix, una vegada i una altra».

A França, Marine Le Pen va comparar la crisi d'immigració de 2015 amb les invasions bàrbares del segle ${ }^{I V}{ }^{13}$ que van provocar el col-lapse de l'Imperi romà. Va donar a entendre que era necessari actuar per a evitar que els bàrbars arribaren a França, la qual cosa significaria, presumiblement, el final de la República Francesa i la civilització moderna d'aquesta.

9 Entrada de Wilders durant ABP: https://www.pvv.nl/12-in-dekamer/spreekteksten/1288-inbreng-wilders-tijdens-apb.html

10 L'última paraula de Geert Wilders sobre el procés: https:// www.pvv.nl/36-fj-related/geert-wilders/3939-het-laatstewoord-van-geert-wilders-bij-het-proces-sp-1560346816.html

11 Entrevista a Geert Wilders al AD: https://www.pvv.nl/36-fjrelated/geert-wilders/9336-interview-geert-wilders-in-het-ad. html

12 Entrevista a Geert Wilders al AD: https://www.pvv.nl/36-fjrelated/geert-wilders/9336-interview-geert-wilders-in-het-ad. html

13 Marine Le Pen compara la crisi dels immigrants amb la caiguda de l'Imperi romà: http://www.lefigaro.fr/politique/ le-scan/citations/2015/09/15/25002-20150915ARTFIG00111marine-le-pen-compare-la-crise-des-migrants-a-la-chutede-l-empire-romain.php
Els exemples anteriors mostren com es construeix una narrativa cultural per mitjà d'una selecció de mentifacts i sociofacts amb l'objectiu d'emfatitzar la imatge d'un poble poderós contra un enemic present i futur. Al mateix temps, remarquen els aspectes més negatius d'aquest «enemic» $\mathrm{O}$ «altre» per mitjà de referències a esdeveniments històrics relacionats amb la cultura del «nosaltres». L'apartat següent tractarà de com contribueixen també els artifacts a la construcció i a la confirmació de la narrativa populista.

En observar els artifacts, hem de fer una distinció entre els que es van crear amb l'objectiu de donar suport al discurs populista i els que no. Gramsci (1971) emprava el terme «intel-lectual orgànic» per a denotar l'intel-lectual que s'identifica amb una classe determinada i parla en nom d'aquesta. Em referiré a la primera categoria com els «autors orgànics» i a la segona com els «autors apropiats».

Un dels primers exemples d'autor orgànic que em ve a la ment quan pense en el context holandés és una pel-lícula curta produïda pel mateix Geert Wilders, Fitna (2008). La cinta pretén ser una crítica a l'islam i mostra fragments de l'Alcorà junt amb imatges de terrorisme islàmic. Amb això tracta de demostrar el perill potencial de l'islam per als Països Baixos, en aquest cas. La pel-lícula és una continuació del programa del partit de Wilders, que vol prohibir la influència islàmica. Aquesta dura crítica contra l'islam i, al mateix temps, una forta defensa de la llibertat d'expressió són potser allò que el va impressionar quan llegia el llibre d'Oriana Fallaci, The Force of Reason; tant que afirma que va decidir fundar el seu propi partit després de llegir-lo. ${ }^{\mathbf{1 4}}$ Wilders va guanyar el premi a la llibertat d'expressió Oriana Fallaci en 2009.

Un altre esdeveniment que va ser primordial per a la carrera política de Geert Wilders és l'assassinat del director de cine holandés Theo van Gogh després del

\footnotetext{
14 Primavera patriòtica a Milà: https://www.nrc.nl/ nieuws/2016/01/30/patriottische-lente-in-milaan1581420-a210117
} 
llançament en 2004 del seu curtmetratge Submission, que és crític amb l'islam. Aquesta pel-lícula i la trista conseqüència que va tenir constitueixen un cas especial que mereix ser investigat amb més detall. Sembla que podria qualificar-se Van Gogh com un autor orgànic, però, al mateix temps, molts altres $\mathrm{s}^{\prime}$ han apropiat de l'esdeveniment del seu assassinat. Es tracta d'un tema candent dins del PVV i una part important de la pel-lícula de Wilders, Fitna. Curiosament, l'esmentat «populista literari» Leon de Winter va escriure la novel-la VSV (2012) sobre la reaparició de Van Gogh com un àngel de la guarda.

Dos exemples d'autors orgànics francesos serien Éric Zemmour i Renaud Camus. El primer va argumentar en l'assaig Le Suicide Français (2014), que a causa de la immigració massiva (musulmana), França ha perdut i continua perdent la seua identitat cultural i la seua autenticitat, d'on sorgeix la idea d'un suïcidi francés. Aquesta mateixa idea de pèrdua cultural també la defén Renaud Camus, autor de Le Grand Remplacement (2011): teoritza que els immigrants musulmans colonitzaran la població nativa, fet que «mutarà» el país i la cultura. Un aspecte important d'aquesta teoria és la complicitat de l'establishment polític en l'àmbit nacional i europeu. Les generoses polítiques d'immigració, impulsades per un pretés odi cap als habitants natius, encoratjarien les persones del Magrib i de l'Àfrica subsahariana a traslladar-se a Europa. Tot i que pot paréixer un discurs bastant marginal, de fet, Marine Le Pen va caracteritzar-lo com un complot. Camus és certament una font d'inspiració per a alguns polítics del PVV, i fins i tot es va unir a una de les manifestacions al mes de gener de 2018. ${ }^{15}$

Un bon exemple de la categoria d'«autor apropiat» és l'escriptor francés Michel Houellebecq. Alguns actors populistes i periodistes de dreta van utilitzar la seua última novel·la, Submissió (2015), que representa la islamització de França en un futur pròxim, per a destacar els perills culturals a què ens enfrontem i

15 Kasteelheer alça l'alarma sobre la cultura europea: https:// www.nrc.nl/nieuws/2018/01/22/kasteelheer-slaat-alarmover-cultuur-van-europa-a1589332 la van vincular amb les idees de Zemmour i Camus. No obstant això, una anàlisi profunda de la novel-la demostra que el verdader objectiu de l'autor és advertir dels perills d'una dicotomia rígida de «bons i roïns», que és precisament l'estratègia dels populistes (Jansma, 2018). En altres paraules, encara que la novel-la no es va concebre com propaganda populista de dreta, sinó al contrari, els populistes de la FN se la van apropiar per a aquest objectiu. Així doncs, això demostra que una novel.la pot arribar a formar part d'una estratègia política, i aprofitar-se per a servir una determinada visió del món i promoure els seus objectius polítics.

\section{CONCLUSIÓ}

Aquest article ha analitzat les diferents formes en què els actors populistes a França i els Països Baixos interactuen amb la cultura. Aquests pareixen poc entusiastes de la cultura «amb C majúscula», la titllen de «passatemps d'esquerra» ${ }^{16}$ i diuen que no ha de rebre subvencions públiques. Tot i això, les referències i l'apropiació de productes culturals són clarament omnipresents en el seu discurs. La cultura té el poder de connectar un poble (una comunitat imaginada) sobre la base de valors i creences compartits, però també de traçar línies definides entre «nosaltres» $\mathbf{i}$ «ells». Així, es construeix una hegemonia de cultures, que pressuposa que la «nostra» cultura és millor que la «seua».

Amb l'objectiu de proporcionar una tipologia del populisme i la cultura, n'he examinat l'ús i l'apropiació que en fan els populistes. Com que havia fet primer la distinció entre artifacts, mentifacts i sociofacts, hem tingut una idea més precisa de l'ampli terme «cultura». He demostrat que els mentifacts i els sociofacts són susceptibles a la reapropiació, les nocions de memòria i oblit (Renan), la tradició inventada (Hobsbawm) i l'emplotment (crear un relat esbiaixat i interessat) de la

\footnotetext{
16 Kabinet posa fi a tots els hobbies de l'esquerra. Originalment publicat en el web www.stopdecrisis.nl, administrat per De Telegraaf, ara accessible en el web de Telegraaf: www. telegraaf.nl/dft/ondernemen/schaduwkabinet/geertwilders/ article20479097.ece
} 
història (Anderson), que són mecanismes importants importants a tenir en compte. Pel que fa als artifacts, he suggerit dues categories diferents, la d'«autor orgànic» i la d' «autor apropiat». En aquest últim cas, no sempre està clar si la interpretació de l'artifact coincideix amb les intencions de l'autor empíric. Per saber-ho, és essencial fer una anàlisi profunda tant de l'artifact com del receptor.

Cal dir que qualsevol intent de traçar línies clares entre artifacts, mentifacts i sociofacts està condemnat al fracàs. Les categoritzacions culturals són rígides però els productes culturals solen ser ambigus i, per tant, tendeixen a desdibuixar-les. En funció del punt de vista, un objecte cultural podria considerar-se tant un mentifact com un sociofact. No obstant això, com hem vist anteriorment, el que ens interessa no és només quines categories de productes culturals conformen la narrativa populista, sinó més aviat com estan associades entre elles $i$, en el seu conjunt, com constitueixen la narrativa populista.

Per garantir un estudi sistemàtic de les pràctiques discursives actuals de l'apropiació cultural és necessària més investigació. En concret, això vol dir que caldria analitzar més productes culturals, però també que l'anàlisi hauria de dur-se a terme a escala més gran, per exemple, utilitzant eines digitals. Aquest enfocament és necessari per a comprendre com una varietat d'actors populistes i no populistes s'involucren en la cultura $i$, en especial, quins en són els patrons lingüístics i els recursos retòrics (Jansma, 2018; Wodak, 2015). Això no només ens proporcionarà les eines per a descodificar la interpretació populista dels productes culturals, sinó que, en un sentit més ampli, revelarà la importància de la cultura per al programa populista. Cal esperar que aquestes idees ajuden a construir una nova narrativa cultural més inclusiva.

\section{REFERÈNCIES BIBLIOGRÀFIQUES}

Anderson, B. (2016). Imagined Communities: Reflections on the Origin and Spread of Nationalism (2a ed.). Londres: Vers. Barker, C. (2000). Cultural Studies. Theory and Practice. Londres: Sage Publications.

Bax, S. (2016). De publieke intellectueel als literair populist. Het publieke schrijverschap van Leon de Winter. Nederlandse Letterkunde, 21(2), 97-129.

Berg-Sørensen, A. (2017). 'Submission': Ambiguity, Hypocrisy and Misanthropy in Michel Houellebecq's Imaginary Politics. Journal of Political Ideologies, 22(2), 131-146.

Brubaker, R. (2017). Between Nationalism and Civilizationism: The European Populist Movement in Comparative Perspective. Ethnic and Racial Studies, 40(8), 1191-1226

Furedi, F. (2018). Populism and the European Culture Wars. The Conflict of Values Between Hungary and the EU. Oxon: Routledge

Gidron, N. i Hall: A. (2017). The Politics of Social Status: Economic and Cultural Roots of the Populist Right. British Journal of Sociology, 68(1), 57-84.

Goodhart, D. (2017). The Road to Somewhere. The Populist Revolt and the Future of Politics. Londres: Hurst \& Co.

Gramsci, A. (1971). Selections from the Prison Notebooks. Nova York: International Publishers.

Hall, S. (1985). Authoritarian Populism: A Reply. New Left Review, O(151), 115-125.

Hall, S. (1986). Gramsci's Relevance for the Study of Race and Ethnicity. Journal of Communication Inquiry, 10(2), 5-27.

Hart, G. (2012). Gramsci, Geography, and the Languages of Populism. En M. Ekers, G. Hart, S. Kipfer i A. Loftus (ed.), Gramsci: Space, Nature, Politics (p. 301-320). Chichester; Malden: Wiley-Blackwell.

Hobsbawm, E. (2012). Introduction: Inventing Traditions. En E. Howsbawm i T. Ranger (ed.), The Invention of Tradition (1-14). Cambridge: Cambridge University Press.

Huxley, J. S. (1955). Evolution, Cultural and Biological. Yearbook of Anthropology, 2-25.

Inglehart, R. i Norris: (2016). Trump, Brexit, and the Rise of Populism: Economic Have-Nots and Cultural Backlash. Harvard Faculty Research Papers. Cambridge, MA: Harvard University. 
Jansma, J. (2018). Populism and Literature: Mapping the Debate on Houellebecq's Soumission. Perspectivas de la Comunicación, 11(1), 7-56.

Judis, J. B. (2016). The Populist Explosion. How the Great Recession Transformed American and European Politics. Nova York: Columbia Global Reports.

Kriesi, H. et al. (2006). Globalization and the Transformation of the National Political Space: Six European Countries Compared. European Journal of Political Research, 45, 921-956.

Laclau, E. (2005). On Populist Reason. Londres: Verso.

McGuigan, J. (1992). Cultural Populism. Londres: Routledge.

Moffitt, B. (2017). Liberal Illiberalism? The Reshaping of the Contemporary Populist Radical Right in Northern Europe. Politics and Governance, 5(4), 112-122.

Mudde, C. (2004). The Populist Zeitgeist. Government and Opposition, 39(4), 541-563.

Mudde, C. i Kaltwasser, C. (2013). Exclusionary vs. Inclusionary Populism: Comparing Contemporary Europe and Latin America. Government and Opposition, 48(2), 147-174.

Mudde, C., i Kaltwasser, C. (2017). Populism: a Very Short Introduction. Oxford: Oxford University Press.

Nachbar, J. i Lause, K. (1992). An Introduction to the Study of Popular Culture: What Is this Stuff that Dreams Are Made Of? En J. Nachbar i K. Lause (ed.). Popular Culture. An Introductory Text (p. 1-35). Bowling Green, OH: Bowling Green State University Press.

Nagle, A. (2017). Kill All Normies. The Online Culture was from Tumblr and 4chan to the Alt-right and Trump. Alresford: Zero Books.

Ossewaarde, M. (2014). The National Identities of the 'Death of Multiculturalism' Discourse in Western Europe. Journal of Multicultural Discourses, 9(3), 173-189.

Paveau, M. A. (1998). Le «roman populiste»: enjeux d'une étiquette littéraire. Mots. Les langages du politique, 55, 45-59.

Rau: (2018). Autumn After the Referendum. En R. Eaglestone (ed.). Brexit and Literature. Critical and Cultural Responses (p. 15-30). Oxon: Routledge.

Renan, E. (1882) What is a Nation? En E. Renan (1992). Qu'est-ce qu'une nation? París: Presses-Pocket.

Rensmann, L. (2017). The Noisy Counter-Revolution: Understanding the Cultural Conditions and Dynamics of Populist Politics in Europe and the Digital Age. Politics and Governance, 5(4) 123-135.

Rodrik, D. (2017). Populism and the Economics of Globalization. Journal of International Business Policy, 1(1-2), 12-33. doi: $10.3386 /$ w23559

Rooduijn, M., De Lange, S. L. i Van der Brug, W. (2014) A Populist Zeitgeist? Programmatic Contagion by Populist Parties in Western Europe. Party Politics, 20(4), 563-575.

Rooduijn, M., Van der Brug, W. i De Lange, S.L. (2016) Expressing or Fuelling Discontent? The Relationship Between Populist Voting and Political Discontent. Electoral Studies, 43, 32-40.

Shaw, K. (2018). BrexLit. En R. Eaglestone (ed.). Brexit and Literature. Critical and Cultural Responses. (15-30). Oxon: Routledge.

Wodak, R., Khosravinik, M. i Mral, B. (ed.) (2013). Right-wing Populism in Europe. Politics and Discourse. Londres: Bloomsbury.

Wodak, R. (2015). The Politics of Fear. What Right-Wing Populist Discourses Mean. Londres: Sage.

\section{NOTA BIOGRÀFICA}

Judith Jansma és estudiant de doctorat en el Departament de Literatura i Cultura Europees en la University of Groningen (Holanda). Té una llicenciatura i màster en Llengua i Cultura Francesa (totes dues en la University of Groningen). El seu projecte de doctorat se centra en les formes en què els populistes a França i els Països Baixos interactuen amb la cultura com a eina per a la construcció identitària. 


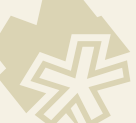

